Discussion Paper No. 08-113

Crowding out Informal Care?

Evidence from a

Social Experiment in Germany

Melanie Arntz and Stephan L. Thomsen

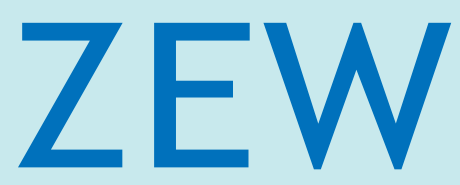

Zentrum für Europäische Wirtschaftsforschung $\mathrm{GmbH}$

Centre for European

Economic Research 
Discussion Paper No. 08-113

\section{Crowding out Informal Care? Evidence from a Social Experiment in Germany}

Melanie Arntz and Stephan L. Thomsen

Download this ZEW Discussion Paper from our ftp server:

ftp://ftp.zew.de/pub/zew-docs/dp/dp08113.pdf

Die Discussion Papers dienen einer möglichst schnellen Verbreitung von neueren Forschungsarbeiten des ZEW. Die Beiträge liegen in alleiniger Verantwortung der Autoren und stellen nicht notwendigerweise die Meinung des ZEW dar.

Discussion Papers are intended to make results of ZEW research promptly available to other economists in order to encourage discussion and suggestions for revisions. The authors are solely responsible for the contents which do not necessarily represent the opinion of the ZEW. 


\section{Das Wichtigste in Kürze}

Prognosen zum demographischen Wandel westlicher Gesellschaften gehen davon aus, dass sich die Zahl hilfebedürftiger Älterer in den nächsten Jahrzehnten verdoppelt, während gleichzeitig die Zahl Angehöriger und ehrenamtlicher Personen, die diese Personen pflegen und unterstützen können, zurückgeht. Einige Vorhersagen gehen daher davon aus, dass für die Aufrechterhaltung des gegenwärtigen Versorgungsniveaus der Pflegeversicherung eine Verdreifachung der Beitragssätze notwendig sein wird. In Anbetracht dieser Umstände hat der Gesetzgeber im Jahr 2002 in einer Erweiterung des Pflegegesetzes die Möglichkeit geschaffen, neue Modelle und Versorgungsformen in der Pflege zu prüfen. Ein wichtiges Programm ist dabei das personengebundene Pflegebudget. Das Pflegebudget bietet die Leistungshöhe der Sachleistung den Pflegebedürftigen in Form eines Budgets, das flexibel für pflegenahe Leistungen und Güter eingesetzt werden kann. Casemanager sollen zudem auf individueller beratend und unterstützend die Verwendung des Budgets begleiten. Das personengebundene Pflegebudget wurde in einem sozialen Experiment in den Jahren 2004 bis 2008 an sieben Standorten getestet. Durch Randomisierung der Teilnehmer in eine Maßnahmegruppe von Budgetbeziehern und eine Kontrollgruppe mit Bezug von Regelleistungen können Unterschiede im Versorgungsniveau kausal dem Pflegebudget zugeordnet werden. Das bestehende System erlaubt zum einen den Bezug von Sachleistungen, die entsprechend einem Katalog von autorisierten Pflegediensten mit Versorgungsvertrag erbracht werden können. Zum anderen können Pflegebedürftige das sog. Pflegegeld wählen, das in seinem Einsatz unbeschränkt ist, aber in der Leistungshöhe etwa der Hälfte der Sachleistungen entspricht. Je nach der zuvor bezogenen Versorgungsart erwarten wir daher unterschiedliche Effekte. Im Vergleich zur Sachleistung kann der Bezug des Pflegebudgets zu einer Verbesserung der Versorgung führen, wenn Leistungen flexibler und besser abgestimmt bezogen werden. Gegenüber dem Pflegegeld ist dieser Effekt nicht zu erwarten, da hier bereits eine flexible Versorgungsform zur Verfügung steht. Vielmehr ist davon auszugehen, dass Pflegehaushalte bisher informell geleistete Pflege nun durch gewerbliche Leistungserbringer substituieren.

Die Evaluation der Effekte des Pflegebudgets im Hinblick auf die Versorgungssituation bestätigen diese Erwartungen empirisch. Während der Bezug des Pflegebudgets zu einer Leistungsausdehnung (gemessen an der Zahl der Pflegestunden) im Vergleich zu den Sachleistungen führt, bleibt der 
Umfang im Vergleich zum Pflegegeld unverändert. Hier substituieren Pflegehaushalte informell erbrachte Pflegeleistungen mit Leistungen privater, gewerblicher Anbieter. 


\section{Non-technical summary}

During the next decades, western societies at a varying speed face a demographic transition that more than doubles the number of elderly individuals in need of long-term care and that at the same time decreases the number of informal caregivers. As a consequence, public responsibility for the provision of long-term care will continue to grow. In the German context, the demographic transition fuels doubts about the fiscal sustainability of the Long-Term Care Insurance (LTCI). According to several forecasts, contribution rates to LTCI would have to triple in the next decades to maintain the current level of support. Since institutionalized care tends to be costly, one way of mitigating the impact of the demographic transition on public expenditures is to strengthen the provision of home care.

The legislator therefore passed an amendment of the LTCI law in 2002 as the legal basis for testing a professionally assisted consumer directed home care program, Personal Budgets, as an alternative to the provision of agency-directed home care. Agency care is restricted to a legally approved and limited catalogue of care services that are provided by authorized agencies only. Personal budgets correspond to the monetary value of agency care, but extend the use of these funds beyond the restrictive catalogue to any care-related services. Due to the extended coverage and the additional assistance of a care manager, personal budgets are likely to produce better care outcomes compared to agency care. However, in case of supplementing the LTCI home care scheme by personal budgets, personal budgets would also compete with cash payments, an unassisted consumer-directed home care program of the LTCI that grants only half the monetary value of personal budgets, but can be spent for any desired services or goods. Cash recipients whose care needs are mainly met by informal care may now choose the more generous personal budget in order to substitute informal by formal care.

Personal budgets were tested in a long-run social experiment that was carried out in seven German counties between 2004 and 2008. Based on the random assignment of participants into a treatment group of personal budget recipients and a control group of standard home care recipients, this paper evaluates the impact of personal budgets on the extent of support by four different types of formal and informal caregivers. The results show that personal budgets increase the amount of care for former recipients of agency care. For former recipients of cash payments the overall time spent 
on care remains unchanged due to a crowding out of informal by formal care. Since we observe a relevant share of cash recipients who switch to personal budgets without any traceable impact on care outcomes, the crowding out induced by the consumer-directed personal budget seems to exceed those of agency-directed home care. 


\title{
Crowding out Informal Care? Evidence from a Social Experiment in Germany.*
}

\author{
Melanie Arntz \\ ZEW Mannheim \\ Stephan L. Thomsen \\ OvG-University Magdeburg \& ZEW Mannheim
}

This version: December 17, 2008

\begin{abstract}
This paper evaluates the effects of a professionally assisted consumer-directed program (Personal Budgets) compared to the standard home care programs of the German long-term care insurance. The evaluation makes use of a long-run social experiment at seven different sites with a random assignment into a treatment group receiving personal budgets and a control group in standard home care programs, i.e. an in-kind benefit (agency care) and cash payments. Compared to agency care personal budgets yield better care outcomes with regard to the overall support of formal and informal caregivers. In contrast, personal budgets do not improve care outcomes compared to the much less generous cash payments due to a strong crowding out of informal by formal care.
\end{abstract}

Keywords: consumer-directed long-term care, social experiment, personal budget, evaluation, Germany

JEL Classification: I38, I12, C93

\footnotetext{
${ }^{*}$ We thank Michael Lechner, Stefan Felder, and Monika Bütler for valuable comments. The paper has also benefited from discussions at seminars of University of Mannheim, University of St. Gallen, University of Göttingen, and the annual meetings of the German Statistical Society and the Verein für Socialpolitik. "Evaluating the use of direct payments in the long term care of the elderly. A social experiment in the context of advancing the compulsory long term care insurance according to $\S 8$ III SGB XI" is gratefully acknowledged. The usual disclaimer applies.

${ }^{\dagger}$ Melanie Arntz (corresponding author) is Senior Research Fellow at Centre for European Economic Research (ZEW) Mannheim, L7, 1 D-68161 Mannheim, e-mail: arntz@zew.de, phone: +49 621 1235159, fax: +49 6211235225.

${ }^{\ddagger}$ Stephan L. Thomsen is Assistant Professor of Labor Economics at Otto-von-Guericke-University Magdeburg and Research Professor at ZEW, Mannheim. Address: Otto-von-Guericke-University, Department of Economics and Management, PO Box 4120, D-39016 Magdeburg, e-mail: stephan.thomsen@ovgu.de, phone: +49 391 6718736, fax: +49 391 6711218. Stephan L. Thomsen thanks the Stifterverband für die Deutsche Wissenschaft (Claussen-SimonStiftung) for financial support.
} 


\section{Introduction}

During the next decades, western societies at a varying speed face a similar challenge: a demographic transition that more than doubles the number of elderly individuals in need of long-term care and that at the same time decreases the number of informal caregivers. As a consequence, public responsibility for the provision of long-term care will continue to grow (see OECD, 2006). Since institutionalized care tends to be costly, current public long-term care programs try to strengthen home care. In particular, much of the debate evolves around the possible advantages of consumerdirected programs compared to the provision of agency care. While in the latter case individuals with care needs receive prescribed services from a publicly authorized agency, consumer-directed programs enable care recipients to act as employers of care assistants and to gain greater control and choice over how to meet their care needs (Stone, 2001).

In the German context, the demographic transition fuels doubts about the fiscal sustainability of its mandatory and non-means tested social Long-Term Care Insurance (LTCI). According to forecasts of Kronberger Kreis (2005), Häcker and Raffelhüschen (2004) and Herzog Commission (2003), original contribution rates to LTCI of 1.7 percent of gross salary would have to triple in the next decades to maintain, ceteris paribus, the current level of support. The LTCI grants benefits for home and nursing home care conditional only on a minimum level of care needs. With the dual purpose of sustaining independent living of older persons and mitigating the impact of the demographic transition on public expenditures for long-term care, the legislator therefore passed an amendment of the LTCI law in 2002 as the legal basis for testing a professionally assisted consumer directed program in a social experiment: Personal Budgets.

In the current system, beneficiaries who opt for home care choose between three programs: an unassisted consumer-directed cash payment, agency care twice the monetary value of the cash option, and a combination of both. Agency care is restricted to a legally approved and limited catalogue of care services that are provided by authorized agencies only. Cash payments, on the other hand, can be spent for any desired services or goods and the program strongly encourages the hiring of relatives and friends. Therefore, all those whose care needs can be met by informal care without any public support have a strong incentive to take advantage of the cash option of the LTCI. Personal budgets, in contrast, are supposed to improve the accommodation of care needs for 
those who - mainly due to a lack of informal caregivers - opt for agency care in the current LTCI system. Thus, personal budgets correspond to the monetary value of agency care, but extend the use of these funds beyond the restrictive catalogue. Moreover, services need no longer be provided by care agencies authorized by the LTCI, but may also be provided by independent and often cheaper caregivers. Due to the extended coverage and the additional assistance of a care manager, personal budgets are likely to produce better care outcomes compared to agency care. At the same time, however, personal budgets may induce a crowding out: Individuals who due to sufficient informal support to meet their care demands would have opted for the less generous cash benefits before may now choose the more generous and compared to agency care less restrictive personal budget in order to substitute informal by formal care (Grabowski, 2006). From an LTCI perspective, this fuels concerns that personal budgets increase overall spending while care outcomes remain rather unchanged for former recipients of cash benefits.

This paper evaluates the impact of personal budgets compared to alternative home care programs based on a social experiment that was carried out in seven German counties between 2004 and 2008 with a random assignment into a treatment group of personal budget recipients and a control group of standard home care recipients. In health policy, program evaluations, especially those based on social experiments, are still in its infancy. A rare exception is the program evaluation of the Cash and Counseling Demonstrations, a comparable social experiment in the context of long-term care programs (Foster, Brown, Phillips, Schore, and Carlson, 2003). Our evaluation thus provides valuable insights in how economic incentives affect the behaviour of households that are struck by the frailty of one of its members. Based on the Personal Budget Demonstrations, the contribution of the paper is twofold. First of all, the paper presents novel evidence on care outcomes of consumer-directed compared to agency-directed care in the German context and thus contributes to the international debate on consumer-directed programs. Secondly, we also examine the relevance of a crowding out for those who currently receive a less generous cash option of the LTCI home care program. To the best of our knowledge, we thus provide the first assessment of whether a consumer-directed compared to an agency-directed home care program crowds out informal care.

For the evaluation of care outcomes, we estimate the effect of personal budgets on the extent of support by four different types of formal and informal caregivers compared to both agency-directed 
care and cash payments. In spite of randomization, we observe some differences between treatment and control group in the outcomes of interest before program start. In addition, we have to deal with some non-random panel attrition. Hence, we apply a difference-in-differences estimator and take account of the non-random nature of panel attrition. The results show that personal budgets increase the amount of care for former recipients of agency care whereas the overall time spent on care remains unchanged for former recipients of cash payments due to a crowding out of informal by formal care. Since we observe a relevant share of cash recipients who switch to personal budgets and for whom LTCI spending doubles without having a traceable impact on care outcomes, we find evidence that the consumer-directed personal budget crowds out informal care to agency care.

The paper is organized as follows: Section 2 provides some institutional background for the German LTCI and information on different international home care programs. Section 3 presents an outline of the social experiment and discusses selected descriptives of the participants. The evaluation strategy is provided in section 4 . Section 5 presents the empirical estimates. In the final section, we discuss our findings in light of both a German and an international policy perspective.

\section{Personal budgets as a complement to current LTCI benefits}

In Germany, individuals are eligible for LTCI benefits if the Medical Review Board approves one of three levels of disability. Eligible individuals in need of care can then choose between three types of home care programs and nursing home care. In the case of home care, the beneficiary can either receive cash benefits or in-kind benefits, so called agency care, twice the monetary value of the cash benefit. In addition, if the monthly claim for agency care is not exhausted, the remaining percentage can be granted as a cash benefit if an informal caregiver takes over the remaining nursing needs. This results in the combination of both types of grants, i.e. mixed benefits, as a third type of home care program. ${ }^{1}$ The existing system of home care provision thus already allows for a high level of flexibility as the client can choose between the extremes of receiving agency care with a minimum of autonomy and the receipt of pure cash payments with a maximum of autonomy as well as a continuum of combinations between these two extremes. In 2006, around a third of beneficiaries

\footnotetext{
${ }^{1}$ As an example, a client in home care who is granted the second level of disability can either receive 410 Euro in cash, 921 Euro in-kind as agency care or any combination between these two. A fifty percent receipt of agency care worth 460 Euro are then complemented by fifty percent of cash benefits, i.e. 205 Euro.
} 
received nursing home care, while almost $50 \%$ opted for cash payments, $9 \%$ received pure agency care and $10 \%$ received a combination of both cash payments and agency care (German Federal Ministry of Health, 2007).

Table 1: Comparison of Personal Budgets with Standard Benefits of LTCI ${ }^{\mathrm{a}}$

\begin{tabular}{llll}
\hline \hline & agency care & cash payments & personal budget \\
\hline $\begin{array}{l}\text { benefit level (in \% } \\
\text { of agency care) }\end{array}$ & $100 \%$ & $44.5-53.5 \%^{\mathrm{b}}$ & $\begin{array}{l}100 \%+\text { overhead for care } \\
\text { management }\end{array}$ \\
\hline $\begin{array}{l}\text { coverage of services } \\
\text { and goods }\end{array}$ & $\begin{array}{l}\text { only services from approved } \\
\text { catalogue provided by autho- } \\
\text { rized agencies }\end{array}$ & none & $\begin{array}{l}\text { any care-related services and } \\
\text { goods; no payment of first- } \\
\text { degree relatives }\end{array}$ \\
\hline monitoring & $\begin{array}{l}\text { yes, by agency services' } \\
\text { provider }\end{array}$ & $\begin{array}{l}\text { no, but semiannual health } \\
\text { checks }\end{array}$ & yes, by care manager \\
\hline $\begin{array}{l}\text { requirement of } \\
\text { benefit exhaustion }\end{array}$ & $\begin{array}{l}\text { no, excess funds are paid as } \\
\text { cash payments (combination } \\
\text { benefits) }\end{array}$ & no & $\begin{array}{l}\text { yes, excess funds have to be } \\
\text { refunded }\end{array}$ \\
\hline \hline
\end{tabular}

a Combination benefits are a mixture of agency care and cash payments depending on the share of agency care spent.

b Level of payments varies according to the level of dependency assigned to the person in need of care.

Table 1 shows that the reform option tested in the demonstration differs from the current home care programs in a number of respects. Compared to agency care that covers only the restrictive list of approved services and have to be provided by an agency that is authorized by the LTCI ${ }^{2}$, personal budgets expand the coverage to any type of care-related services and allow for the hiring of independent workers. Moreover, a mandatory care management is supposed to help clients to implement a care arrangement that best suits their needs. Former evaluations of consumerdirected programs in the US and the Netherlands as well as evaluations of the cash option in the Austrian and German long-term care insurance suggest that clients who self-direct their home care arrangement gain control and express a higher level of satisfaction than agency-directed clients (Benjamin, Matthias, and Franke, 2000 and Foster, Brown, Phillips, Schore, and Carlson, 2003, Miltenburg and Ramakers, 1999). Furthermore, concerns regarding a lower quality of care provision in the case of consumer-directed programs could not be confirmed (Badelt, Holzmann-Jenkins, Matul, and Österle, 1997, Nemeth and Pochobradsky, 2004, and Schneekloth and Müller, 2000, Foster, Brown, Phillips, Schore, and Carlson, 2003). Moreover, there is evidence that consumerdirected care increases total service hours because due to a missing overhead and lower fringe benefits the hiring of independent workers is less costly than the hiring of agency workers (Benjamin, Matthias, and Franke, 2000). For an international review of consumer-directed programs see Kodner

\footnotetext{
${ }^{2}$ These agencies have to fulfill certain criteria concerning the organization and quality of care.
} 
(2003), Wiener, Tilly, and Cuellar (2003), Tilly and Wiener (2001), and Lundsgaard (2005). In light of this international literature, the consumer-directed personal budget may thus yield better care outcomes per Euro spent by the German LTCI than agency care. ${ }^{3}$

Predictions regarding the effects of personal budgets compared to the cash option of the LTCI are more difficult, as there are differences not only in coverage, assistance, and monitoring, but also in the level of granted benefits. Concerning the benefit level, personal budgets grant the monetary value of agency care as a cash payment to the client, and thus correspond to twice the benefit level of the existing cash option. As a disadvantage, however, services and goods covered by personal budgets are restricted compared to the cash option. While cash benefits can be considered as an income supplement that can be used for any goods and services, personal budgets necessitate the use of the funds for care-related goods and services and also preclude the hiring of first-degree relatives, i.e. spouses and children. Moreover, the compliance with these regulations is monitored by a care manager who assists the client in organizing an adequate care plan and monitors the adequacy of care provision. Despite these restrictions, the monetary advantage of personal budgets compared to cash payments and the extended coverage compared to agency care are likely to make personal budgets an attractive alternative for at least some share of cash recipients. For them, personal budgets are likely to foster the purchase of services provided by independent care providers, but it is unclear to what extent the additional financial resources are used to increase total service hours or to simply reduce the burden of informal caregivers.

According to the literature, individuals with sufficient informal support to meet their care demands are likely to participate in home care programs in order to substitute informal by formal care (Grabowski, 2006). Indeed, empirical studies confirm a substitution effect between informal and formal care (Greene, 1983; Hanley, Wiener, and Harris, 1991; Ettner, 1994, Pezzin, Kemper, and Rechovsky, 1996). Moreover, home care programs often have little or no retarding effect on the probability of entering a nursing home (Christianson, 1988; Wooldridge and Schore, 1988). One likely reason for this finding is that these programs reduce nursing home use only among certain sub-groups (Greene, Lovely, and Ondrich, 1993), while most recipients of public home care would not have entered a nursing home for a substantial time period irrespective of the receipt of publicly

\footnotetext{
${ }^{3}$ We cannot in general evaluate the cost efficiency of personal budgets as we lack information on the administrative cost as well as on the costs of the care management.
} 
financed services (Weissert, Cready, and Pawelak, 1988). Hence, the empirical literature indicates that publicly provided formal home care may crowd out informal care which results in increasing public long-term care expenditure while total care provided remains constant. Such crowding out effects could even be stronger for the less restrictive consumer-directed as compared to agencydirected home care (Grabowski, 2006) because the latter is less of a substitute for privately funded home care. If this was the case, we should observe a relevant share of cash recipients that opt for personal budgets and at the same time observe a strong substitution between informal by formal care. In fact, the need to refund any cash that has not been spent for care-related services at the end of the month (see Table 1) may especially encourage individuals to substitute informal by formal care.

Depending on the benchmark home care program, personal budgets thus correspond to very different treatments and should be examined separately. Irrespective of the benchmark, however, personal budgets are likely to alter care arrangements with regard to the amount of support by different types of caregivers. We thus examine the extent of support measured in terms of hours of care provided by week for four types of caregivers: (i) relatives and (ii) friends and volunteers as informal caregivers, and (iii) agency workers working for agencies that are authorized by the LTCI and (iv) independent workers who provide services without being contracted by the LTCI as formal caregivers. For lack of a better measure of the achieved level of health and care, we additionally examine the total hours of care provided by all caregivers as a proxy of the attained care level. Similar to van Houtven and Norton (2008), we thus assume one hour of care to be comparably effective for all types of carers. ${ }^{4}$ For previous recipients of agency care, we expect a partial substitution of agency by independent care providers so that total hours of care provided per week may increase. For former cash recipients, independent workers are likely to substitute for informal support and the expected effect on total hours of care is unclear.

\footnotetext{
${ }^{4}$ If the quality of care provided per hour differs across providers, one would like to estimate effects in terms of standardized care hours. Since there is no information in the data to define an adequate weighting scheme, we have to stick to this assumption.
} 


\section{Personal Budget Demonstrations}

Conducted as a social experiment with a random assignment of all program participants into treatment and control group, the Personal Budgets Demonstrations provide the means to empirically examine the effect of personal budgets on the extent of support of formal and informal caregivers compared to the currently available home care grants. Personal Budgets took place in seven German counties between 2004 and $2008 .^{5}$ Sites were chosen to include both rural and urban regions as well as regions in eastern and western Germany, but cannot be considered to be representative for Germany as a whole. Still, the counties cover a wide range of regions, from the rural and unemployment-struck Annaberg in eastern Germany to urban and prospering regions in western Germany. ${ }^{6}$ This mixture of sites at least ensures that Personal Budgets is implemented under quite different regional conditions in terms of both the supply of and the demand for care services.

The control group continued to receive agency care, cash payments, or a combination of both, while the treatment group received the personal budget with additional support from a care manager. The minimum requirement for being eligible to participate was to be eligible for LTCI benefits. In addition, at five of the sites, access to Personal Budgets was granted only to home care recipients with a share of agency care of at least 50\%. At only two sites, all individuals irrespective of the current choice of benefit were eligible for participation because the initial focus of Personal Budgets was on the comparison of agency-directed and consumer-directed care. Before assigning participants to either the treatment or control group, a base interview was conducted by local care managers. The purpose of this base interview was to collect information concerning the demographic and socioeconomic background of the elderly person and his/her household as well as the current organization of care. In addition, information was collected on the care recipient's abilities to accomplish basic activities of daily life such as dressing, preparation of food, housekeeping, being mobile, shopping etc. In cases in which the care recipient was not able to answer the survey on his own, the main caregiver, mostly a close relative, was asked to answer the questionnaire instead. ${ }^{7}$

\footnotetext{
${ }^{5}$ Personal Budgets was launched on behalf of the association of compulsory health insurers (Verband der deutschen Angestelltenkassen, VdAK). It was carried out under the supervision of the polytechnical university in Freiburg (Evangelische Fachhochschule Freiburg, EFH) and accompanying research was accomplished by the Centre for European Economic Research (ZEW Mannheim) and a sociological research institute in Freiburg (FIFAS, Freiburg).

${ }^{6}$ It should be noted that one site (Munich) could not be used for evaluation. The control group design was abandoned at this site because the local target group of individuals who leave hospitalization had proven to be very reluctant to participate in a random assignment. The following analysis thus leaves out these participants.

${ }^{7}$ Around $30 \%$ of the interviews could be conducted with the care recipient only. In $50 \%$ of the cases, the interview
} 
Semiannual follow-up interviews with the care recipients were conducted by the care managers in case of the treatment group and by additional interviewers in case of the control group. The contents of the follow-up interviews correspond to the base interview excluding all questions on time-invariant background characteristics.

Table 2: Number of Treatment and Control Group Interviews by Former Benefit Receipt ${ }^{\mathrm{a}}$

\begin{tabular}{lrrrrrrrr}
\hline \hline Former benefit receipt & \multicolumn{3}{c}{ Treatment group } & \multicolumn{4}{c}{ Control group } \\
& base & fup6 & fup12 & fup18 & base & fup6 fup12 & fup18 \\
\hline Agency care & 122 & 99 & 79 & 59 & 39 & 25 & 17 & 10 \\
Cash payment & 94 & 73 & 56 & 45 & 66 & 43 & 22 & 13 \\
Mixed benefits & 58 & 44 & 32 & 18 & 25 & 14 & 8 & 4 \\
Initial claim & 36 & 28 & 18 & 10 & 19 & 12 & 4 & 3 \\
\hline Total & 310 & 244 & 185 & 132 & 149 & 94 & 51 & 30 \\
\hline \hline &
\end{tabular}

Table 2 contains the number of available treatment and control group interviews by the type of former benefit receipt which deserves a number of remarks: First, for those who claimed LTCI benefits for the first time or previously received mixed benefits, we do not know the treatment as it may be an unknown mixture of two heterogenous treatments. We therefore restrict our analysis to those previously receiving agency care or cash payments. Second, there are more than 300 base interviews in the treatment group and only 150 in the control group. This excessive assignment into the treatment group is due to the fact that - for political reasons - random assignment had been suspended during the early in-take period. If care managers took advantage of this suspension period by actively promoting the project among those they considered the most needy, this may have introduced a selection into the treatment group that needs to be accounted for in the evaluation design. Third, the share of participants with a follow-up interview after one year is around $40 \%$ for the treatment group, but less than $30 \%$ in the control group. This above-average panel attrition on the part of the control group may be due to a lack of motivation as they do not directly benefit from participating in Personal Budgets. If attrition is non-random and related to care outcomes, our evaluation strategy will have to take account of panel attrition. Moreover, due to decreasing numbers of observations, we restrict the evaluation to the treatment effects within one year of program participation. Finally, despite the intake of former cash recipients being restricted to two was conducted with both the care recipient and the main caregiver, while $20 \%$ of the interviews were pure proxy interviews with the main caregiver. 
sites, we have a relevant number of former cash recipients in our sample. An important condition for personal budgets to crowd out informal care compared to agency care is fulfilled: personal budgets are attractive to at least some share of former cash recipients. In fact, in the two counties where program eligibility was not restricted to recipients of agency care, the share of home care recipients who participated in the demonstration was $5.5 \%$ among recipients of agency care, $3.5 \%$ among mixed benefit recipients and 3.4\% among cash benefit recipients. Among those who contacted the local care management office for further information on Personal Budgets, $40 \%$ of all agency care recipients, $44 \%$ of all mixed benefit recipients, and $32 \%$ of all cash benefit recipients decided to participate in the program. On the one hand, these figures suggest that personal budgets are not equally attractive to all home care recipients. On the other hand, the participation rates imply that the share of former cash recipients opting for program participation in order to receive the personal budget is not negligible and only somewhat lower than the participation rate for recipients of agency care.

Sample descriptives can be found in Table B.1 in the Appendix. If random assignment to the treatment group had been successful, sample characteristics at the time of the base interview should be comparable for treaties and controls. At least for some characteristics - e.g., the county of residence, age, pre-treatment care arrangement - we do find some imbalances between both subgroups though. Moreover, even if the sample was perfectly balanced at first, panel attrition may result in a non-comparable treatment and control group in the course of time. The next section further examines the relevance of possible sample selection issues based on multivariate analyses and develops an adequate evaluation strategy in order to identify the effect of personal budgets on the support of different groups of caregivers.

\section{Estimation Strategy}

The standard framework in microeconomic evaluation of treatment effects is the potential outcome approach dating back to Roy (1951) and Rubin (1974) with two potential outcomes $Y^{1}$ (individual receives treatment) and $Y^{0}$ (individual does not receive treatment). The observed outcome for any

individual $i$ can be written as: $Y_{i}=Y_{i}^{1} \cdot D_{i}+\left(1-D_{i}\right) \cdot Y_{i}^{0}=Y^{0}+D_{i}\left(Y^{1}-Y^{0}\right)$, where $D \in\{0,1\}$ is a 
binary treatment indicator. The treatment effect for each individual $i$ is the difference between the potential outcomes $\Delta_{i}=Y_{i}^{1}-Y_{i}^{0}$. Since one of the outcomes is unobservable for each individual, we have to concentrate on population averages of gains from treatment instead of calculating individual effects directly. In particular the average treatment effect on the treated (ATT) for those who actually participate in the program is given by

$$
\Delta_{A T T}=E(\Delta \mid D=1)=E\left(Y^{1} \mid D=1\right)-E\left(Y^{0} \mid D=1\right) .
$$

The problem in estimating this treatment effect is that the second term in eq. 1 is unobservable. In experimental data, treatment $D$ is randomized across eligible persons so that the potential outcomes $Y^{0}$ and $Y^{1}$ are statistically independent of the treatment indicator. It follows that $E\left(Y^{0} \mid D=1\right)=$ $E\left(Y^{0} \mid D=0\right)$ holds and we can use the nonparticipants to adequately estimate the counterfactual outcome. Thus, social experiments have been considered as the ideal way to evaluate the impacts of programs. $^{8}$

However, problems in the implementation of Personal Budgets may give rise to biases. ${ }^{9}$ First of all, randomization into treatment and control group may be incomplete due to suspending the random assignment at the beginning of the project. The differences between treatment and control group in the descriptive statistics in Table B.1 already point towards a possible selection of individuals into treatment. In order to further examine the reliability of randomization, we estimate a binary probit model of the probability of assignment to the treatment group. We include regressors that, on the one hand, may affect the assignment process and that, on the other hand, may influence care outcomes. Apart from basic socio-demographic characteristics such as age, gender and marital status and information on household size and number of children, we take account of individual care needs, i.e. the level of dependency that is granted by the LTCI as well as a care needs index that reflects an individual's care needs based on the self-assessed need to receive help with relevant activities of daily life. We further include care outcomes before program start such as the number of care hours provided by informal and formal caregivers. In addition, we control for the regional context by including dummies for the six program sites. Table 3 provides separate estimates for former recipients of cash payments and agency care.

\footnotetext{
${ }^{8}$ See Orr (1999) and Smith (2000) for a comprehensive discussion of social experiments.

${ }^{9}$ See Bijwaard and Ridder (2005) and Heckman and Smith (1995) for a discussion of possible sources for biases.
} 
Table 3: Probit Estimates on Randomization

\begin{tabular}{|c|c|c|}
\hline & $\begin{array}{c}\text { Agency Care } \\
\text { Recipients } \\
\text { Coeff. }\end{array}$ & $\begin{array}{c}\text { Cash Recipients } \\
\text { Coeff. }\end{array}$ \\
\hline \multicolumn{3}{|l|}{ Demographics } \\
\hline age & -0.0605 & 0.0069 \\
\hline age $^{2}$ & 0.0006 & -0.0001 \\
\hline female & -0.2910 & 0.1750 \\
\hline married & $0.7367^{* *}$ & -0.4930 \\
\hline \multicolumn{3}{|c|}{ Number of children (in reference to one child) } \\
\hline none & $-0.7227^{*}$ & -0.0490 \\
\hline two or more & -0.6288 & 0.0295 \\
\hline further person in household & 0.2528 & -0.2226 \\
\hline \multicolumn{3}{|c|}{ Program site (in reference to Annaberg) } \\
\hline Erfurt & $-1.2158^{* *}$ & 0.4437 \\
\hline Kassel & -0.9623 & - \\
\hline Marburg & $-1.5084^{* *}$ & - \\
\hline Neuwied & -0.9634 & - \\
\hline Unna & -0.7274 & - \\
\hline \multicolumn{3}{|c|}{ Need of care (in reference to LTCI-grade 1 ) } \\
\hline health index & -0.0040 & 0.0117 \\
\hline LTCI-grade 2 & -0.0032 & $-0.6595^{* *}$ \\
\hline LTCI-grade 3 & -0.0024 & -0.0194 \\
\hline \multicolumn{3}{|l|}{ Care arrangement } \\
\hline hours of informal care per week & 0.0027 & $0.0046^{*}$ \\
\hline hours of formal care per week & 0.0081 & 0.0076 \\
\hline help from relatives & -0.0852 & -0.1860 \\
\hline help from friends and volunteers & -0.1218 & $0.5462^{* *}$ \\
\hline help from authorized agencies & 0.1473 & -0.4485 \\
\hline help from independent workers & -0.2085 & -0.2012 \\
\hline Constant & 3.4462 & -0.5936 \\
\hline \multicolumn{3}{|l|}{ Statistics } \\
\hline pseudo $R^{2}$ & 0.1628 & 0.1316 \\
\hline $\mathrm{N}$ & 161 & 160 \\
\hline
\end{tabular}

Stars denote significance on $10 \%(*), 5 \%(* *)$ and $1 \%(* * *)$ level.

If participation in the treatment group was completely random, none of the covariates should have a significant effect. However, program sites significantly affect the probability of being in the treatment group for former agency care recipients. Moreover, some socio-demographic variables as well as the care needs affect the assignment into the treatment group. For characteristics that affect both the selection into the treatment group and the outcome of interest, this implies a selection on observables that can be taken care of by including relevant characteristics as covariates in the outcome equation. However, Table 3 indicates that for former recipients of cash benefits, preprogram care arrangements significantly affect the probability of being treated despite controlling for observable individual and household characteristics. This suggests a selection on unobservables that violates the identifying assumption of the social experiment.

We remedy this problem by applying a difference-in-differences approach (DiD, see e.g. Ashenfelter and Card, 1985) that controls for pre-program differences in outcomes for the treatment and the 
control group. The crucial assumption for the validity of the DiD-estimates is that in the absence of treatment, the average outcomes for the treated and controls would have followed parallel paths over time (Abadie, 2005). In case pre-treatment characteristics that are associated with the dynamics of the outcome are unbalanced between treatment and control group, this assumption may be violated. In our case, this would mean that the differences in the extent of hours in the care arrangement prior to participation are due a individual-transitory shock. A possible example for such a shock is the anticipation of the individuals of being assigned to the treatment group. If persons expect to be assigned to the treatment group, they may change their care arrangement in advance which would result in the observed differences. Unfortunately, we have no information on earlier time periods to test the existence of such a shock. We thus have to assume that such transitory shocks do not exist and bias our estimates.

The corresponding DiD-estimator for outcome $y_{i t}$ can be written as

$$
y_{i t}=\beta_{0}+\beta_{1} \text { treat }+\delta_{0} t_{2}+\delta_{1} t_{3}+\delta_{2} \text { treat } \times t_{x=2,3}+\delta_{3} \text { treat } \times t_{3}+\mathbf{x}_{\mathbf{i}}^{\prime} \boldsymbol{\beta}+c_{i}+u_{i t},
$$

where treat is a dummy variable capturing differences between treatment and control group before program start at $t_{1} . t_{2}$ and $t_{3}$ are dummy variables for the follow-up interviews six and twelve month after program start. These dummies take account of aggregate factors affecting $y$ in the absence of the program. $\delta_{2}$ is the parameter estimate of the treatment effect, defined as the interaction of $t_{2}$ and treat. $\delta_{3}$ allows this treatment effect to differ with an increasing duration of the program. $\mathbf{x}_{\mathbf{i}}$ is a matrix of additional covariates such as program site or socio-demographic characteristics that may be relevant for both the selection into treatment and the outcome of interest. These covariates refer to the time-constant pre-program characteristics. In addition, we allow for an unobservable individual effect $c_{i}$. How to estimate eq. 2 consistently and efficiently depends on the assumptions that we are willing to make with regard to the relationship between $c_{i}$ and the observable covariates, especially the treatment indicator.

If $c_{i}$ is uncorrelated to the observed explanatory variables included in eq. 2, pooled OLS with standard errors that are robust to individual clustering may yield consistent estimates for the linear outcomes of care hours per week. If, in addition, the idiosyncratic error term is not only uncorrelated to the contemporaneous explanatory variables, but to observable covariates in each time period, we may apply a random effects panel estimator to potentially gain efficiency. However, $c_{i}$ may be related 
to the treatment indicator. In particular, $c_{i}$ might capture financial resources of the household or the willingness of relatives and friends to support the elderly person. If these omitted characteristics affect both the selection into the treatment group as well as care outcomes, estimation by a pooled or random effects panel estimator yield biased results. In order to allow for an arbitrary correlation between the unobserved individual effect and observable covariates, a fixed effects estimator may be applied. Due to demeaning, however, the time-constant $x_{i}$ cannot be identified in this model.

An additional challenge to consistently estimate the parameters of interest is panel attrition. In the case of fixed effects estimation, sample selection due to panel attrition is only a problem if the selection process is related to the idiosyncratic error term $u_{i t}$. Whether this is the case can be tested by including a lagged indicator of attrition in the fixed effects estimation. The extended fixed effects estimations of eq. 2 suggest, however, that sample selection is fully absorbed by $c_{i}$. Fixed effects estimations thus need not be corrected for sample selection in our case. Any estimator that assumes $c_{i}$ to be uncorrelated to the observable covariates, however, will be biased if panel attrition is nonrandom and not fully captured by the observables in eq. 2 . To take account of panel attrition in the pooled and random effects estimation, one possibility is to use the two-step procedure suggested by Heckman (1979). In the standard set-up, the first stage consists of estimating a selection equation and computing an omitted variable bias correction term. Let $Z_{i t}$ be a binary indicator denoting participation in each group in period $t=2,3$ :

$$
Z_{i t}=1\left(\mathbf{w}_{\mathbf{i t}}{ }^{\prime} \boldsymbol{\alpha}_{\boldsymbol{i}}+v_{i t}>0\right)
$$

$\left(Z_{i t}, \mathbf{w}_{\mathbf{i t}}\right)$ are always observed. Moreover, assume $v \sim N(0,1)$ and $(u, v)$ to be independent of $\mathbf{w}$ with zero mean, and $E(u \mid v)=\gamma v$. Without loss of generality, we assume $\operatorname{Var}(v)=1$ since $Z_{i t}$ is a dummy variable. Then, we can estimate eq. 3 by a binary probit model for each time period $t=2,3$

$$
P\left(Z_{i t}=1 \mid \mathbf{w}_{\mathbf{i t}}\right)=\Phi\left(\mathbf{w}_{\mathbf{i t}}{ }^{\prime} \boldsymbol{\alpha}_{\boldsymbol{i}}\right)
$$

We estimate this selection equation separately for the treatment and control group in order to allow for different attrition processes. Based on eq. 4, we calculate the inverse Mills ratios as $\hat{\lambda}_{i t}=\lambda_{i t}\left(\mathbf{w}_{\mathbf{i t}}{ }^{\prime} \hat{\boldsymbol{\alpha}}_{\boldsymbol{i}}\right)=\phi\left(\mathbf{w}_{\mathbf{i t}}{ }^{\prime} \hat{\boldsymbol{\alpha}}_{\boldsymbol{i}}\right) / \Phi\left(\mathbf{w}_{\mathbf{i t}}{ }^{\prime} \hat{\boldsymbol{\alpha}}_{\boldsymbol{i}}\right)$. We stack the $\hat{\lambda}_{i t}$ of the two groups into one vector $\hat{\lambda}_{t}$. In a second stage, we then augment eq. 2 to

$$
y_{i t}=\beta_{0}+\beta_{1} \text { treat }+\delta_{0} t_{2}+\delta_{1} t_{3}+\delta_{2} \text { treat } \times t_{x=2,3}+\delta_{3} \text { treat } \times t_{3}+\mathbf{x}_{\mathbf{i}}^{\prime} \boldsymbol{\beta}+\gamma_{0} \hat{\lambda}_{t_{2}}+\gamma_{1} \hat{\lambda}_{t_{3}}+c_{i}+u_{i t},
$$


which can be estimated on the unbalanced sample by pooled OLS or a random effects panel estimator.

For identification, estimation of eq. 5 necessitates exclusion restrictions that influence the panel attrition but not the outcomes, i.e. $\mathbf{x}_{\mathbf{i t}}$ in eq. 5 has to be a subset of $\mathbf{w}_{\mathbf{i t}}$ in eq. 3 . Hence, changes in the care context of the participant (e.g. a shock to the available informal support) that likely affect outcomes are not suitable as exclusion restrictions. Instead, we use two exclusion restrictions capturing program conditions that may affect attrition but not care outcomes. First of all, drop offs of interviewers may reduce the probability to participate in follow-up interviews as it may be an obstacle to discuss intimate aspects with a new interviewer. Throughout the demonstration about $25 \%$ of the interviewers in the control group had to be substituted by a new interviewer. In the treatment group, however, interviews were conducted by care managers among whom attrition occurred only once. As an additional exclusion restriction, we therefore use the gap measured in days between the last interview and the fixed and exogenously determined end date of data collection because we observe some variation in the availability of interviews with an increasing gap. Although interviews are supposed to take place every six month, there seem to be delays in some cases. This may be either due to limited availability of the participants and their proxy respondents or problems in the coordination of the appointments of the interviews. In our case, the probability to participate in follow-up interviews increases with an increasing gap, but at a diminishing rate. To cover such non-linearities, we also include a quadratic of the gap in eq. 3. First stage estimates of eq. 3 can be found in Appendix A and reveal that panel attrition is systematically related to a number of individual and household-related characteristics. Moreover, the exclusion restrictions are highly significant and have the expected sign.

In the subsequent analyses, we test for robustness of results by comparing pooled with random and fixed effects panel estimators. For pooled and random effects estimates, we only show results for the augmented outcome equation 5 that takes account of panel attrition because corresponding estimates do not differ substantially from estimates that do not control for non-random panel attrition. ${ }^{10}$

\footnotetext{
${ }^{10}$ Estimates for equation 2 are available from the authors upon request.
} 


\section{Results}

We now present the results on the extent of support by the caregivers, i.e. the weeks hours provided. As mentioned above, we distinguish two groups of informal caregivers, relatives and friends and volunteers, as well as two groups of formal caregivers, authorized care agencies and independent providers in the empirical analysis. Table 4 provides separate estimates for former recipients of agency care and cash payments. Besides the variables of interest, we also included a number of covariates in the estimation. ${ }^{11}$ We only display the effect of the treatment group indicator treat, the treatment effect treat $\times t_{2,3}$ and the selection terms accounting for non-random panel-attrition $\lambda_{2,3}$. Table 4 also shows the corresponding effects on the total hours of care provided per week while Table 5 displays the aggregate result for informal and formal caregivers.

Table 4 suggests heterogeneous effects of personal budgets depending on the type of benefit an individual received previously. Compared to agency-directed care, personal budgets do not reduce the support by relatives or friends and volunteers. Moreover, the effect on the hours of care provided by independent providers is large with about 11.7 (pooled estimation) to 13.2 (fixed effects estimation) hours per week after six months and intensifies by an additional 7.3 (random effects estimation) to about 7.9 (fixed effects estimation) hours per week after one year. Thus, the total effect is to increase the weekly hours provided by independent workers by around 20 hours. Given these findings, it is of little surprise that we also find at least some weakly significant evidence for an expansion of total care hours. While total care hours after six month increase by insignificant three to six hours depending on the estimator, there is some significant expansion of total care hours after one year of 15 to 18 hours per week according to the pooled and random effects estimates. Individuals who previously opted for agency care mainly due to insufficient informal support seem to use personal budgets to partially substitute care provided by authorized agencies by independent providers while maintaining the limited support by informal caregivers. Since independent workers are cheaper, care recipients are now able to purchase more formal care hours. Of course, the quality of service provision by independent providers may be worse than those provided by well-qualified agency workers. However, care recipients still employ agency workers and only seem to shift certain

\footnotetext{
${ }^{11}$ The other variables regarded in the estimation are age, age (squared), female, married, further person living in household, frequently contact with friends, number of children (categorial), level of care granted by LTCI (categorial), care index and program site (categorial). Full estimates including all covariates are available from the authors upon request.
} 
Table 4: Effects on care hours per week provided by different care providers for former recipients of cash payments and agency services ${ }^{\mathrm{a}}$

\begin{tabular}{|c|c|c|c|c|c|c|}
\hline & \multicolumn{3}{|c|}{ Agency Care } & \multicolumn{3}{|c|}{ Cash Payments } \\
\hline & $\mathrm{PO}$ & $\mathrm{RE}$ & $\mathrm{FE}$ & $\mathrm{PO}$ & $\mathrm{RE}$ & $\mathrm{FE}$ \\
\hline \multicolumn{7}{|l|}{ Relatives } \\
\hline$t_{2}$ & 2.972 & 4.255 & 5.6179 & 2.450 & 3.178 & 4.341 \\
\hline$t_{3}$ & 2.704 & 6.062 & 8.6277 & 8.378 & 5.269 & 4.602 \\
\hline treat & 5.884 & 4.127 & & 11.673 & 11.151 & \\
\hline treat $\times t_{x=2,3}$ & -3.723 & -4.923 & -6.0459 & $-14.781^{*}$ & $-16.620^{* *}$ & $-18.845^{* *}$ \\
\hline treat $\times t_{3}$ & 8.741 & 6.234 & 4.8961 & -8.540 & -6.221 & -5.094 \\
\hline$\lambda_{2}$ & $47.726^{* *}$ & 43.400 & & 6.368 & -0.835 & \\
\hline$\lambda_{3}$ & -9.704 & -10.268 & & 3.699 & 4.711 & \\
\hline $\mathrm{N}$ & 161 & 161 & 161 & 160 & 160 & 160 \\
\hline \multicolumn{7}{|c|}{ Friends and volunteers } \\
\hline$t_{2}$ & -0.686 & -0.609 & -0.196 & -0.425 & -0.349 & -0.239 \\
\hline$t_{3}$ & -0.434 & -0.172 & 0.617 & -1.127 & -1.558 & -1.551 \\
\hline treat & 0.085 & 0.075 & & $10.821^{* * *}$ & $10.474^{* * *}$ & \\
\hline treat $\times t_{x=2,3}$ & 0.429 & 0.362 & -0.019 & $-6.639 * *$ & $-5.507^{* *}$ & -4.986 \\
\hline treat $\times t_{3}$ & 1.194 & 0.991 & 0.568 & 1.971 & 1.347 & 1.243 \\
\hline$\lambda_{2}$ & 1.104 & 0.804 & & -5.873 & -3.741 & \\
\hline$\lambda_{3}$ & -0.535 & -0.442 & & 1.840 & 0.675 & \\
\hline $\mathrm{N}$ & 161 & 161 & 161 & 160 & 160 & 160 \\
\hline \multicolumn{7}{|c|}{ Authorized care agencies } \\
\hline$t_{2}$ & 1.682 & 1.813 & 1.893 & -0.129 & -0.157 & -0.166 \\
\hline$t_{3}$ & -0.028 & 0.780 & 1.275 & 0.229 & 0.111 & 0.081 \\
\hline treat & 1.821 & 1.938 & & -0.486 & -0.601 & \\
\hline treat $\times t_{x=2,3}$ & -2.154 & -2.731 & $-3.473^{* *}$ & 0.569 & 0.608 & 0.614 \\
\hline treat $\times t_{3}$ & 0.784 & -0.057 & -0.605 & -0.080 & -0.033 & -0.020 \\
\hline$\lambda_{2}$ & -5.171 & -4.437 & & -0.614 & -0.8232 & \\
\hline$\lambda_{3}$ & 1.111 & 0.877 & & 0.628 & 0.5737 & \\
\hline $\mathrm{N}$ & 161 & 161 & 161 & 160 & 160 & 160 \\
\hline \multicolumn{7}{|c|}{ Independent providers } \\
\hline$t_{2}$ & -4.143 & -4.752 & -5.993 & 1.861 & 0.880 & 1.078 \\
\hline$t_{3}$ & -2.971 & -4.444 & -6.431 & 1.915 & 1.533 & 2.751 \\
\hline treat & 0.916 & 0.752 & & 2.002 & 1.317 & 1.782 \\
\hline treat $\times t_{x=2,3}$ & $11.730^{* *}$ & $12.210^{* * *}$ & $13.216^{* *}$ & 7.733 & $8.152^{*}$ & $8.818^{*}$ \\
\hline treat $\times t_{3}$ & $7.362^{* *}$ & $7.855^{*}$ & 8.276 & 2.473 & 2.346 & 0.487 \\
\hline$\lambda_{2}$ & -4.185 & -5.085 & & 16.370 & $13.620^{*}$ & \\
\hline$\lambda_{3}$ & 2.727 & 2.422 & & -5.168 & -4.595 & \\
\hline $\mathrm{N}$ & 161 & 161 & 161 & 160 & 160 & 160 \\
\hline \multicolumn{7}{|c|}{ Total of care hours } \\
\hline$t_{2}$ & -0.174 & 0.284 & 1.321 & 3.739 & 3.599 & 4.209 \\
\hline$t_{3}$ & -0.728 & 1.415 & 4.089 & 9.408 & 5.125 & 4.234 \\
\hline treat & 8.706 & 7.131 & & $23.737^{* * *}$ & $22.035^{* *}$ & \\
\hline treat $\times t_{x=2,3}$ & 6.283 & 5.232 & 3.679 & -12.301 & $-13.000^{*}$ & $-14.187^{*}$ \\
\hline treat $\times t_{3}$ & $18.080^{* * *}$ & $15.362^{*}$ & 13.136 & -5.101 & -3.193 & -2.301 \\
\hline$\lambda_{2}$ & $39.474^{* *}$ & 34.822 & & 16.470 & 7.139 & \\
\hline$\lambda_{3}$ & -6.401 & -7.308 & & 0.783 & 1.461 & \\
\hline $\mathrm{N}$ & 161 & 161 & 161 & 160 & 160 & 160 \\
\hline
\end{tabular}

Stars denote significance on $10 \%\left(^{*}\right), 5 \%(* *)$ and $1 \%\left(^{* * *}\right)$ level.

${ }^{a}$ Estimations include age, age (squared), female, married, further person living in household, frequently contact with friends, number of children (categorial), level of care granted by LTCI (categorial), care index and program site (categorial) as additional covariates.

$\mathrm{PO}=$ pooled sample (cross-section estimation) $\mathrm{RE}=$ random effects panel model, $\mathrm{FE}=$ fixed effects panel model. See text for details.

tasks to independent providers. Thus, if one is willing to assume that independent providers fulfill these care tasks with a similar level of quality as agency workers, personal budgets tend to allow for 
an expansion of support at identical cost (abstracting from the costs for the caremanagers). This indicates efficiency gains of personal budgets compared to agency care.

Table 5: Effects on care hours per week provided by different care providers for former recipients of cash payments and agency services $^{\mathrm{a}}$

\begin{tabular}{|c|c|c|c|c|c|c|}
\hline & \multicolumn{3}{|c|}{ Agency Care } & \multicolumn{3}{|c|}{ Cash Payments } \\
\hline & $\mathrm{PO}$ & $\mathrm{RE}$ & FE & $\mathrm{PO}$ & $\mathrm{RE}$ & $\mathrm{FE}$ \\
\hline \multicolumn{7}{|c|}{ Informal caregivers } \\
\hline$t_{2}$ & 2.286 & 3.642 & 5.421 & 2.025 & 2.895 & 4.102 \\
\hline$t_{3}$ & 2.270 & 5.906 & 9.245 & 7.251 & 3.591 & 3.051 \\
\hline treat & 5.969 & 4.304 & & $22.493^{* *}$ & $21.618^{* *}$ & \\
\hline treat $\times t_{x=2,3}$ & -3.294 & -4.564 & -6.064 & $-21.419 * *$ & $-22.497^{* * *}$ & $-23.831^{* * *}$ \\
\hline treat $\times t_{3}$ & $9.934^{*}$ & 7.205 & 5.464 & -6.569 & -4.683 & -3.851 \\
\hline$\lambda_{2}$ & $48.830^{* *}$ & $44.218^{*}$ & & 0.495 & -5.481 & \\
\hline$\lambda_{3}$ & -10.240 & -10.605 & & 5.540 & 5.631 & \\
\hline $\mathrm{N}$ & 161 & 161 & 161 & 160 & 160 & 160 \\
\hline \multicolumn{7}{|c|}{ Formal caregivers } \\
\hline$t_{2}$ & -2.460 & -3.149 & -4.100 & 1.732 & 0.733 & 0.107 \\
\hline$t_{3}$ & -2.999 & -4.026 & -5.156 & 2.144 & 1.657 & 1.183 \\
\hline treat & 2.737 & 2.654 & & 1.516 & 0.735 & \\
\hline treat $\times t_{x=2,3}$ & $9.576^{* *}$ & $9.596^{* *}$ & $9.743^{* *}$ & $8.303^{*}$ & $8.755^{*}$ & $8.877^{* *}$ \\
\hline treat $\times t_{3}$ & $8.145^{* *}$ & $7.851^{*}$ & 7.672 & 2.393 & 2.309 & 2.434 \\
\hline$\lambda_{2}$ & -9.356 & -9.774 & & 15.757 & 12.839 & \\
\hline$\lambda_{3}$ & 3.839 & 3.203 & & -4.540 & -4.017 & \\
\hline $\mathrm{N}$ & 161 & 161 & 161 & 160 & 160 & 160 \\
\hline \multicolumn{7}{|c|}{$\begin{array}{l}\text { Stars denote significance on } 10 \%(*), 5 \%(* *) \text { and } 1 \%(* * *) \text { level. } \\
\text { de age, age (squared), female, married, further person living in } \\
\text { ntly contact with friends, number of children (categorial), level } \\
\text { LTCI (categorial), care index, and program site (categorial) as } \\
\text { tes. }\end{array}$} \\
\hline
\end{tabular}

With regard to former cash recipients, the picture clearly differs. We now find a significant and strong reduction of support by relatives with about 14.8 (pooled estimation) to 18.9 (fixed effects estimation) less hours of support per week. This strong finding may reflect two institutional features of the personal budget compared to the cash option: the interdiction of remunerating close relatives and the extension of the benefit level as a means of increasingly purchasing formal care. The second feature is more likely to drive the observed changes in the care arrangement because the amount of hours spent by friends and volunteers whose payment is not restricted by the personal budget is strongly reduced as well. Table 5 thus indicates that service hours provided by informal caregivers decrease by more than 20 hours, while support by formal caregivers increases by around 8 hours per week. This latter finding is driven by extended support by independent providers as shown in Table 4. Adding these opposing effects together, there is some evidence that total care hours per week decrease for former recipients of cash payments (but the statistical significance of the estimates is 
weak). This need not imply reduced level of care provision though if the quality of care provided per hour by an independent providers exceeds the quality of informal care. Nevertheless, the results clearly indicate a strong substitution of informal care by formal care for former cash recipients. Since all these individuals previously did not switch to the more generous agency care, but did so only for the less restrictive consumer-directed personal budget, we argue that personal budgets lead to a crowding out of informal care compared to agency care.

\section{Conclusion}

Based on the Personal Budget Demonstrations long-run social experiment at seven German sites, this paper has evaluated the impact of personal budgets on care outcomes compared to the two main home care programs currently available from the LTCI, agency care and cash benefits. Despite the experimental design, we have applied a difference-in-differences estimators in order to take account of possible self-selection and correct our estimates for non-random panel attrition.

For former recipients of agency care, our findings indicate that the support by agency workers is partially substituted by less costly independent workers, while support by informal caregivers remains unchanged. The evidence is also indicative for rising total hours of care provided per week. If we assume a comparable care quality of agency and independent workers, this finding therefore suggests that personal budgets may be a means to improve care outcomes per Euro of benefits that is granted by the LTCI. Our results thus confirm the favourable findings of similar international evaluations of consumer-directed compared to agency-directed programs. While this is a highly desirable outcome from the perspective of the LTCI, the implementation of personal budgets as an additional home care program also hinges on the effects personal budgets exert on former recipients of the less generous cash benefit. The corresponding results indicate a relevant shift of cash recipients to the personal budget for whom a strong substitution of informal care by formal care increases LTCI spending without increasing the total hours of care provided per week. In the context of the German long-term care system that offers agency care as well as a less generous cash benefits to its home care beneficiaries, the transition to an extended LTCI scheme that includes personal budgets tends to crowd out informal care to a non-negligible extent. This is because personal budgets are 
less restrictive in use than agency care and are therefore a closer substitute for privately funded home care that directly compete with the informal provision of care.

Despite the German specifics, we think that our findings are also relevant for international scholars and policy advisors. In particular, we would like to argue that in a system with a public provision of either agency-directed or consumer-directed care, the moral hazard of participating in such public programs despite having sufficient informal care should be stronger for consumer-directed as compared to agency-directed care. This is what Grabowski (2006) named the woodwork effect that is the equivalent to the crowding out of informal care among former cash recipients in the German context. Since we are not aware of any attempts to assess - depending on the specifics of the country's long term care provision - the additional crowding out or moral hazard that is induced by consumer-directed compared to agency-directed care, we therefore encourage scholars from other countries to provide further evidence on this issue. 


\section{References}

Abadie, A. (2005): "Semiparametric Difference-in-Differences Estimators," Review of Economic Studies, 72(1), 1-19.

Ashenfelter, O., AND D. CARD (1985): "Using the Longitudinal Structure of Earnings to Estimate the Effect of Training Programs," The Review of Economics and Statistics, 67(4), 648-660.

Badelt, C., A. Holzmann-Jenkins, C. Matul, And A. Österle (1997): "Analyse der Auswirkungen des Pflegevorsorgesystems (Analysis of the care system)," Report, Bundesministerium für Arbeit, Gesundheit und Soziales, Wien.

Benjamin, A. E., R. E. Matthias, and T. M. Franke (2000): "Comparing Client-Directed and Agency Moels for Providing Supportive Services at Home," Health Services Research, 35(1), $351-366$.

BijwaArd, G., And G. Ridder (2005): "Correcting for Selective Compliance in a Re-employment Bonus Experiment," Journal of Econometrics, 125(1-2), 77-111.

Christianson, J. (1988): "The Effect of Channeling on Informal Care Caregiving," Health Services Research, 23(1), 99-118.

Ettner, S. (1994): "The Effect of the Medicaid Home Care Benefit on Long-Term Care Choices of the Elderly," Economic Inquiry, 32(1), 103-127.

Foster, L., R. Brown, B. Phillips, J. Schore, and B. L. Carlson (2003): "Improving the Quality of Medicaid Personal Assistance through Consumer Direction," Health Affairs, pp. 162-175, Web Exclusive.

German Federal Ministry of Health (2007): "Vierter Bericht über die Entwicklung der Pflegeversicherung," Berlin.

Grabowski, D. C. (2006): "The Cost-Effectiveness of Noninstitutional Long-Term Care Services: Review and Synthesis of the Most Recent Evidence," Medical Care Research and Review, 63(1), $3-28$. 
Greene, V. L. (1983): "Substitution Between Formally and Informally Provided Care for the Impaaired Elderly in the Community," Medical Care, 21(6), 609-619.

Greene, V. L., M. E. Lovely, And J. I. Ondrich (1993): "Do Community-Based, Long.TermCare Services Reduce Nursing Home Use? A Transition Probability Analysis," The Journal of Human Resources, 28(2), 297-317.

Hanley, R., J. Wiener, and K. Harris (1991): "Will Paid Home Care Erode Informal Care Support?," Journal of Health Politics, Policy and Law, 16(3), 507-521.

Häcker, J., And B. RAffelhüschen (2004): "Denn sie wussten, was sie taten: Zur Reform der sozialen Pflegeversicherung," DIW Vierteljahreshefte zur Wirtschaftsforschung, 73(1), 158-174.

Heckman, J. J. (1979): "Sample Selection Bias as a Specification Error," Econometrica, 47(1), $153-161$.

Heckman, J. J., And J. A. Smith (1995): "Assessing the Case for Social Experiments," Journal of Economic Perspectives, 9(2), 85-110.

Herzog Commission (2003): "Endbericht der Kommission zur Reform der sozialen Sicherungssysteme," Kommission 'Soziale Sicherheit' im Auftrag des CDU-Bundesvorstandes, Berlin.

Kodner, D. (2003): "Consumer-Directed Services: Lessons and Implications for Integrated Systems of Care," International Journal of Integrated Care, 17, serial online.

Kronberger Kreis (2005): "Tragfähige Pflegeversicherung," Donges, J. B. and Eekhoff, J. and Franz, W. and Fuest, C. and Möschel, W. and Neumann, M. J., Frankfurt/Main.

LundsgaARD, J. (2005): "Consumer Direction and Choice in Long-Term Care for Older Persons, Including Payments for Informal Care: How Can it Help to Improve Care Outcomes, Employment and Fiscal Sustainability," OECD Health Working Papers, No. 20, OECD.

Miltenburg, F. M., And C. C. Ramakers (1999): "Evaluatie-onderzoek persoonsgebonden budget in Nederland (Evaluation of personal care budgets in the Netherlands)," Tijdschrift voor gezondheidswetenschappen, 77(7), 422-429. 
Nemeth, C., And E. Pochobradsky (2004): "Qualitätssicherung in der häuslichen Betreuung," Report, Österreichisches Bundesinstitut für Gesundheitswesen, Bundesministeriums für soziale Sicherheit, Generationen und Konsumentenschutz.

OECD (2006): "Projecting OECD Health and Long-term Care Expenditures. What Are the Main Drivers?," Oecd economics department working papers no. 477, OECD publishing.

OrR, L. (1999): Social Experiments: Evaluating Public Programs with Experimental Methods. SAGE Publications Inc., Thousand Oaks.

Pezzin, L. E., P. Kemper, and J. Rechovsky (1996): "Does Publicly Provided Home Care Substitute for Family Care? Experimental Evidence with Endogeneous Living Arrangements," The Journal of Human Resources, 31(3), 650-676.

Roy, A. (1951): "Some Thoughts on the Distribution of Earnings," Oxford Economic Papers, 3, $135-145$.

Rubin, D. (1974): "Estimating Causal Effects to Treatments in Randomised and Nonrandomised Studies," Journal of Educational Psychology, 66, 688-701.

Schneekloth, U., And U. MÜller (2000): Wirkungen der Pflegeversicherung, vol. 127 of Schriftenreihe des Bundesministeriums für Gesundheit. Nomos-Verlag, Baden-Baden.

Smith, J. A. (2000): "A Critical Survey of Empirical Methods for Evaluating Active Labor Market Policies," Schweizerische Zeitschrift für Volkswirtschaft und Statistik, 136(3), 1-22.

Stone, R. I. (2001): "Providing Long-Term Care Benefits in Cash: Moving to a Disability Model," Health Affairs, 20(6), 96-108.

Tilly, J., And J. M. Wiener (2001): "Consumer-Directed Home and Community Services: Policy Issues," Occasional paper no. 44, The Urban Institute, Washington D.C.

van Houtven, C., And E. Norton (2008): "Informal care and Medicare expenditures: Testing for heterogeneous treatment effects," Journal of Health Economics, 27, 134-156.

Weissert, W., C. Cready, and J. Pawelak (1988): "The Past and Future of Home and Community Based Long Term Care," The Milbank Quarterly, 66, 309-388. 
Wiener, J. M., J. Tilly, and A. E. Cuellar (2003): "Consumer-Directed Home Care in the Netherlands, England, and Germany," report, AARP Public Policy Institute.

Wooldridge, J., And J. Schore (1988): "The Effect of Channeling on the Use of Nursing Homes," Health Services Research, 23(1), 119-128. 


\section{A Appendix}

The inverse Mills ratio terms included in the estimation of the treatment effects are computed based on separate first stage estimates on panel attrition for treatment and control group and for the different types of benefits received before program. The results are, however, comparable to

Table A.1: Probit Estimates on Panel Attrition before the first and the second follow-up interview

\begin{tabular}{|c|c|c|c|c|}
\hline & \multicolumn{2}{|c|}{$\begin{array}{l}\text { Drop off before first } \\
\text { follow-up }\end{array}$} & \multicolumn{2}{|c|}{$\begin{array}{c}\text { Drop off before second } \\
\text { follow-up }\end{array}$} \\
\hline & Controls & Treated & Controls & Treated \\
\hline & Coeff. & Coeff. & Coeff. & Coeff. \\
\hline \multicolumn{5}{|l|}{ Exclusion Restrictions } \\
\hline gap in days & $0.4851 * * *$ & $0.1535^{* * *}$ & $0.4283^{* * *}$ & $0.3790 * * *$ \\
\hline $\operatorname{gap}^{2}$ & $-0.3146^{* * *}$ & $-0.0856^{* *}$ & $-0.2404^{* * *}$ & $-0.2090 * * *$ \\
\hline interv. left program & $-1.4061^{* * *}$ & 0.5879 & $-1.0779 * * *$ & 0.1931 \\
\hline \multicolumn{5}{|c|}{ Sociodemographics and household context } \\
\hline age & $-0.1188^{*}$ & -0.0607 & 0.0479 & -0.0402 \\
\hline $\operatorname{age}^{2}$ & $0.0010^{*}$ & 0.0004 & -0.0005 & 0.0003 \\
\hline female & -0.2900 & 0.1677 & -0.4169 & $0.4623^{* *}$ \\
\hline married & -0.1815 & 0.2946 & -0.2158 & 0.1665 \\
\hline additional household member & 0.7248 & 0.1110 & 0.5257 & -0.0847 \\
\hline regular contact to friends & $0.7034^{* *}$ & 0.1107 & $0.5087^{*}$ & $0.3622^{* *}$ \\
\hline \multicolumn{5}{|c|}{ Number of children (in reference to one child) } \\
\hline none & -0.7844 & -0.0493 & 0.8391 & 0.2862 \\
\hline two or more & -0.3215 & -0.0949 & 0.7292 & 0.1308 \\
\hline \multicolumn{5}{|c|}{ Level of care granted by LTCI (in reference to grade 1) } \\
\hline LTCI-grade 2 & -0.4650 & 0.3547 & 0.4831 & 0.1952 \\
\hline LTCI-grade 3 & -0.5684 & 0.1766 & 0.7024 & 0.0069 \\
\hline care needs index $(0-100)$ & $0.0236^{* *}$ & $-0.0177^{* * *}$ & 0.0041 & $-0.0101^{*}$ \\
\hline \multicolumn{5}{|c|}{ Type of benefits before program (in reference to initial claim) } \\
\hline agency care & $1.4147^{* *}$ & 0.0926 & 0.7854 & 0.3616 \\
\hline cash payments & $1.5442^{* * *}$ & -0.3329 & $1.0446^{*}$ & -0.2241 \\
\hline mixed benefits & 0.3568 & -0.1023 & 0.6408 & -0.1057 \\
\hline \multicolumn{5}{|c|}{ Program site (in reference to Annaberg and Kassel) } \\
\hline Erfurt & $-3.2585^{* * *}$ & 0.4962 & -0.4093 & 0.0864 \\
\hline Marburg & $-1.8933^{* *}$ & $0.5132^{*}$ & 0.7053 & $0.5212^{*}$ \\
\hline Neuwied & $-2.5367^{* * *}$ & $0.6098^{* *}$ & -0.2602 & $0.6609^{* *}$ \\
\hline Unna & $-2.3399^{* *}$ & $0.6009^{*}$ & 0.2143 & 0.2479 \\
\hline Constant & -0.8023 & 1.5433 & $-8.1328^{* * *}$ & $-3.3132^{* *}$ \\
\hline \multicolumn{5}{|l|}{ Statistics } \\
\hline pseudo $R^{2}$ & 0.3605 & 0.1153 & 0.3196 & 0.2472 \\
\hline $\mathrm{N}$ & 149 & 310 & 149 & 310 \\
\hline
\end{tabular}

the corresponding estimates for the full sample which we therefore display in Table A.1 instead. We estimate separate models of panel attrition between waves 1 and 2 and waves 1 and 3 . The results show that the exclusion restrictions are able to capture panel attrition. With an increasing gap between the date of the first interview and the date of data transfer the probability of being observed in the panel increases in both groups as well as for both intervals (waves 1 and 2,1 and 
3). The change of the care manager or interviewer between two interviews affects the probability negatively in the control group only; for the treatment group no significant difference could be established. In addition, age, social relationships (further person in the household, close friend available, having a child) affect the panel survival probability.

\section{B Tables}

Table B.1: Selected Descriptives and $t$-Tests of Equality or $\chi^{2}$-Tests of Independence (means, wave 1)

\begin{tabular}{|c|c|c|c|c|c|c|c|c|c|}
\hline & \multicolumn{3}{|c|}{ Full Sample } & \multicolumn{3}{|c|}{ Cash Payments } & \multicolumn{3}{|c|}{ Agency Care } \\
\hline & Treaties & Controls & $p$-value & Treaties & Controls & $p$-value & Treaties & Controls & $p$-value \\
\hline \multicolumn{10}{|l|}{ Sociodemographics } \\
\hline age (years) & 74.5 & 71.9 & 0.10 & 73.0 & 72.3 & 0.84 & 74.1 & 69.2 & 0.04 \\
\hline female & 0.64 & 0.67 & 0.95 & 0.70 & 0.64 & 0.39 & 0.64 & 0.69 & 0.54 \\
\hline married & 0.29 & 0.31 & 0.59 & 0.29 & 0.41 & 0.12 & 0.28 & 0.13 & 0.03 \\
\hline \multicolumn{10}{|l|}{ Number of Children } \\
\hline none & 0.23 & 0.25 & & 0.23 & 0.23 & & 0.25 & 0.38 & \\
\hline one & 0.23 & 0.15 & & 0.17 & 0.18 & & 0.25 & 0.08 & \\
\hline two and more & 0.55 & 0.60 & 0.20 & 0.60 & 0.59 & 0.98 & 0.50 & 0.54 & 0.05 \\
\hline \multicolumn{10}{|l|}{ Need of care } \\
\hline care needs index ${ }^{\mathrm{a}}(1-100)$ & 66.2 & 63.9 & 0.29 & 66.1 & 61.0 & 0.13 & 63.7 & 60.5 & 0.39 \\
\hline LTCI-level 1 & 0.55 & 0.54 & & 0.58 & 0.58 & & 0.58 & 0.64 & \\
\hline LTCI-level 2 & 0.32 & 0.36 & & 0.28 & 0.38 & & 0.30 & 0.26 & \\
\hline LTCI-level 3 & 0.13 & 0.09 & 0.42 & 0.14 & 0.04 & 0.13 & 0.12 & 0.10 & 0.81 \\
\hline \multicolumn{10}{|l|}{ Care arrangement } \\
\hline total care hours/week & 64.5 & 55.2 & 0.09 & 86.4 & 62.5 & 0.02 & 41.1 & 31.1 & 0.15 \\
\hline informal care hours/week & 51.0 & 41.7 & 0.11 & 73.8 & 53.6 & 0.06 & 27.1 & 18.7 & 0.19 \\
\hline formal care hours/week & 13.6 & 13.5 & 0.97 & 12.6 & 8.9 & 0.45 & 14.0 & 12.4 & 0.72 \\
\hline help from relatives & 0.76 & 0.79 & 0.52 & 0.81 & 0.85 & 0.51 & 0.70 & 0.62 & 0.30 \\
\hline help from friends/volunteers & 0.33 & 0.25 & 0.07 & 0.41 & 0.23 & 0.01 & 0.25 & 0.33 & 0.33 \\
\hline help from agency workers & 0.62 & 0.54 & 0.09 & 0.16 & 0.26 & 0.13 & 0.88 & 0.87 & 0.93 \\
\hline help from independent worker & 0.38 & 0.40 & 0.65 & 0.36 & 0.42 & 0.42 & 0.34 & 0.36 & 0.88 \\
\hline \multicolumn{10}{|l|}{ Program site } \\
\hline Annaberg & 0.08 & 0.03 & & 0.00 & 0.00 & & 0.14 & 0.03 & \\
\hline Erfurt & 0.15 & 0.19 & & 0.23 & 0.20 & & 0.17 & 0.31 & \\
\hline Kassel & 0.13 & 0.08 & & 0.00 & 0.00 & & 0.20 & 0.21 & \\
\hline Marburg & 0.15 & 0.18 & & 0.00 & 0.00 & & 0.20 & 0.31 & \\
\hline Neuwied & 0.37 & 0.48 & & 0.73 & 0.80 & & 0.13 & 0.10 & \\
\hline Unna & 0.10 & 0.04 & 0.01 & 0.00 & 0.00 & 0.58 & 0.16 & 0.05 & 0.07 \\
\hline \multicolumn{10}{|l|}{ Type of benefits before program } \\
\hline initial claim & 0.12 & 0.13 & & 0.00 & 0.00 & & 0.00 & 0.00 & \\
\hline agency care & 0.39 & 0.26 & & 0.00 & 0.00 & & 1.00 & 1.00 & \\
\hline cash payments & 0.30 & 0.44 & & 1.00 & 1.00 & & 0.00 & 0.00 & \\
\hline mixed benefits & 0.19 & 0.17 & 0.01 & 0.00 & 0.00 & & 0.00 & 0.00 & \\
\hline observations & 310 & 149 & & 94 & 66 & & 122 & 39 & \\
\hline
\end{tabular}

a The care index is based on the self-assessed ability to accomplish activities of daily life. The index is constructed to be 100 in case of full dependence on care and support by others. 